\title{
REVISIÓN CRÍTICA DE LOS ESTUDIOS RECIENTES SOBRE EL ORIGEN Y LA TRANSFORMACIÓN DE LA CUBA COLONIAL AZUCARERA Y ESCLAVISTA
}

\section{CRITICAL REVIEW OF RECENT STUDIES ON THE ORIGIN AND TRANSFORMATION OF COLONIAL SUGAR AND SLAVERY CUBA}

\author{
Antonio Santamaría García \\ Instituto de Historia, Centro de Humanidades y Ciencias Sociales, Consejo Superior \\ de Investigaciones Sociales, Madrid, España, <a_santamaria_garcia@yahoo.es>
}

\begin{abstract}
Resumen. Recientemente se han publicado muchos estudios sobre la industria azucarera de Cuba que han actualizado la historiografía y su participación en los debates internacionales. Este artículo analiza los referidos al lapso 1765-1898, entre el inicio de la expansión del sector usando trabajo esclavo, en torno a lo cual se redefinió el pacto colonial con España, y la transformación que sufrió tras las abolición y en el que acabó el colonialismo hispano. Quedan aspectos por analizar y los años 1870-1898 carecen de suficiente investigación, pero el avance en el conocimiento ha sido notable, se han explorado épocas y asuntos hasta ahora ignotos y superado sesgos y tópicos anteriores. Por ejemplo, se muestra que la redefinición del colonialismo español fue coherente en sus circunstancias, que es discutible hablar de una contradicción entre esclavitud y cambio tecnológico o que los azucareros criollos no fueron sujetos pasivos en las redes mercantiles y financieras de su negocio.
\end{abstract}

Palabras clave: azúcar; economía; historiografía.

Abstract. Recently have been published many studies about of the Cuban sugar industry, who have updated the historiography and its participation in international debates. This paper analyzes these studies about $1765-1898$ period, between the origin of the expansion of such industry using slave work, an around it was redefined the colonial pact with Spain, and the transformation that suffered after the abolition, and which ended Spanish colonialism. Remain issues to study and the years 1870-1898 are not sufficiently researched, but the progress in the knowledge has been remarkable, times and matters until now unknown have been explored and gaps and stereotypes inherited have been avoided. For example it been shown the redefinition of Spanish colonialism was consistent in their circumstances, it cannot speak of contradiction between slavery and technological change, or that the sugar creoles were not passive subject in the commercial and financial networks of their business.

Key words: sugar, economy, historiography.

Fecha de recepción: julio de 2013. Fecha de aceptación: septiembre de 2013.

Am. Lat. Hist. Econ., año 21, núm. 2, mayo-agosto, 2014, pp. 168-198 
$\mathrm{E}$ 1 ingenio, dice Lezama Lima, es "un arcado del que sólo los cubanos conocen el secreto". En efecto, pese a su crisis tras el fin de la Europa socialista, su casi único mercado, la del azúcar, sigue siendo la principal industria histórica de $\mathrm{Cuba},{ }^{2}$ lo que más ha determinado su economía, sociedad, cultura, y los estudios al respecto no han sufrido una crisis como la productiva. De hecho su calidad y cantidad recientes precisan un estado de la cuestión por lo mucho que aportan. Este trabajo propone realizarlo, aunque limitado a lo publicado en el siglo XXI y sobre el lapso de 1765 a 1898, pues una perspectiva más ambiciosa requeriría mayor espacio, y aquel periodo es el que ha recibido más atención.

\section{SOMERO BALANCE DE MEMORIA}

La historia azucarera y económica de Cuba cuenta con varios balances anteriores que evitan una larga exposición de los precedentes para valorar las aportaciones recientes. ${ }^{3}$ Esos estudios coinciden en que hasta finales del siglo XVIII no se generalizaron plantaciones como las del Caribe británico o francés gracias a la conjunción entonces de reformas en su economía y relación colonial y de empresarios capaces de aprovecharlas para elevar la competitividad de sus ingenios cuando pudieron importar masivamente esclavos, trabajadores empleados en las Antillas extranjeras, ocasión que proveyó la revolución de Haití (1791), que dejó a merced de los demás productores el mercado que abastecía y los africanos que adquiría ese territorio. ${ }^{4}$

Aunque inicialmente la industria azucarera se estudió en el contexto de la sociedad económica cubana o con una dilatada cronología, ${ }^{5}$ progresivamente el interés se centró en el periodo esclavista decimonónico. Ese sesgo se debió en parte a la trascendencia de El ingenio, de Moreno Fraginals, aunque tenía antecedentes en Cepero o Ely, y se unió al hecho

${ }^{1}$ Lezama, "Introducción”, 1987, p. IX.

${ }^{2}$ Su producción pasó de 7567000 toneladas por año en 1978-1992 a 1400000 en 2012.

${ }^{3}$ Piqueras, "Azúcar", 1999; Roldán, Historia, 2001; García-Álvarez y Santamaría, "Azúcar”, 2005; Santamaría y García-Mora, "Donde”, 2005; Santamaría, "Nuevos”, 2005, y García-Álvarez y García-Mora, Textos, 1998.

4 Arango, "Discurso", 1998.

${ }^{5}$ Véanse Guerra, Azúcar, 1927; Ortiz, Contrapunteo, 1973, pioneros de esos estudios; Friedlaender, Historia, 1944; Abad, Azúcar, 1945; Marrero, Cuba, 1972-1992; Goizueta-Mino, Azúcar, 1974; Le Riverend, Historia, 1985, y el estudio internacional comparado Deerr, History, 1951. 
de que, por la especialización productiva de la isla, su historiografía económica ha sido prioritaria, incluso deformadamente azucarera. ${ }^{6}$

Hay que señalar, además, que los estudios sobre esclavitud tienen sus propias características y precisarían un análisis tan amplio como este. ${ }^{7}$ De ahí que aquí sólo se tratarán en sus aspectos vinculados a la producción azucarera. Por ejemplo, los debates acerca de la rentabilidad del trabajo esclavo o las causas de su abrogación siguen abiertos, y apenas se ha analizado el mercado laboral posabolición salvo en investigaciones dedicadas a la inmigración, muy numerosas, que analizaron sus flujos y rasgos principales y las diferencias entre la que llegó a Cuba en época esclavista y después, cuando la isla se convirtió en destino de migración masiva.

Los estudios migratorios tienen también su propia historiografía y está vinculada con la del sistema colonial. De él se ha dicho que, junto con la esclavitud -por ser trabajo imprescindible del ingenio- y al carecer España de un mercado para la producción azucarera en la que se especializaba Cuba, se basó en los vínculos de negocios entre las elites insulares y metropolitanas. Esto dio lugar a una economía y sociedad en las que coexistieron formas de avanzado capitalismo tecnológico y comercial y un régimen laboral compulsivo, pero que dejó espacios (cultivo de alimentos, abastecimieno urbano) que aprovecharon, por ejemplo, los canarios, llegados a la isla en gran cantidad en época esclavista. De ahí que la investigación sobre el tema haya derivado desde hace tiempo al análisis de problemas como la formación de imaginarios e identidades colectivas, relacionadas con los new cultural studies. ${ }^{8}$

La deformación azucarera de la historiografía cubana afectó incluso a los sectores vinculados a la oferta del dulce. Por ejemplo sus derivados (licores, confituras) no han sido estudiados. No ocurre igual con el ferrocarril público, que por su relación con los ingenios se extendió velozmente por el oeste insular desde 1837, pero sí con el dedicado al servicio interno de las plantaciones, cuya extensión $(12000 \mathrm{~km})$ duplicaría a la del anterior. Su construcción empezó en las décadas finales del siglo XIX que, como

\footnotetext{
${ }^{6}$ Moreno-Fraginals, Ingenio, 1978; Cepero, Azúcar, 1947, y Ely, Cuando, 1963.

${ }^{7}$ La historiografía es abundante. Véanse Barcia, "Esclavitud", 1994, las compilaciones de Moreno-Fraginals et al., Slavery, 1985; Solano y Guimerá, Esclavitud, 1990; el estudio clásico de Pérez de la Riva, Barracón, 1987, o la estimación del precio de los esclavos en Bergad et al., Cuban, 1995.

${ }^{8}$ Los estudios migratorios también están vinculados con los del comercio, empresas y finanzas por la importancia de los españoles en tales actividades en Cuba. Para la historiografía existente véanse Bahamonde y Cayuela, Hacer, 1992; Maluquer, Nación, 1992; Naranjo, "Población”, 1994; Naranjo y García-González, Racismo, 1996; Paz y Hernández, Esclavitud, 1992, las investigaciones sobre otras migraciones compulsivas llevadas a la isla desde la década de 1840, cuando empezaron a existir problemas para proseguir la trata negrera, Pérez de la Riva, Historia, 1976; García-Álvarez, "Traficantes", 1993, y los balances en Hernández, "Historiografía", 1997, y Naranjo y Santamaría, "España”, 2000.
} 
dijimos, han sido poco investigadas, y fue parte de una transformación mayor de la agroindustria cañera, mediante la cual adoptó las tecnologías de la segunda revolución industrial y se concentró para hacer frente a la creciente competencia y a los problemas causados por la abolición. Además, puesto que Cuba estaba poco poblada, estos se afrontaron recurriendo a la citada migración en masa, lo que explica que, a su vez, los ingenios descentralizasen su oferta de caña, dejándola en manos de colonos más o menos independientes. ${ }^{9}$

Con aspectos bien analizados para la época esclavista, como el comercio o la tecnología, ocurría igual que con el ferrocarril: apenas contaban con investigaciones sobre los años $1870-1900 .{ }^{10} \mathrm{Y}$ el déficit de estudios era aún mayor en temas o enfoques como la tierra, las finanzas, la historia regional y local o empresarial o la aplicación de métodos económicos y estadísticos. ${ }^{11}$

En síntesis, al acabar el siglo xx la industria azucarera cubana contaba con muchos y buenos estudios del periodo esclavista, pero requería del análisis de sectores vinculados; de factores productivos; sobre su efecto económico, poblacional y medioambiental, y de las épocas anterior y posterior a la citada. Además, era preciso enriquecerlos con nuevos enfoques y métodos, con las posibilidades derivadas de los new cultural studies y de otros más tradicionales, regionales, económicos y estadísticos, empresariales, comparados. ${ }^{12}$ Recientemente se ha avanzado notablemente en la solución de algunos déficits, no de todos, como veremos enseguida, y el volumen y calidad de los estudios son positivos.

\section{INVENCIÓN DE LA CUBA AZUCARERA}

Las etapas de intensa transformación productiva (final del siglo XVIII, inicio del XIX y el ocaso de esa última centuria), eran las peor estudiadas por su complejidad y la dificultad de hallar fuentes. Varios estudios recientes

\footnotetext{
${ }^{9}$ Véanse Zanetti y García-Álvarez, Caminos, 1987; Santamaría, "Ferrocarril”, 1998, y Santamaría y García-Mora, "Colonos", 1998.

${ }^{10}$ Véanse Maluquer, "Mercado", 1974; Zanetti, Cautivos, 1989, o los estudios de las relaciones Cuba-Estados Unidos, donde se concentraron progresivamente las exportaciones azucareras de la isla en el siglo XIX, Jenks, Cuban, 1929; Mullins, Sugar, 1964; Pérez, Cuba, 1990, y MartínezFernández, Torn, 1994.

${ }^{11}$ Véanse Iglesias, "Azúcar”, 1988; García-López, "Comerciantes”, 1996; Pérez de la Riva, Origen, 1946; Le Riverend, Problemas, 1987; Iglesias, "Tierra", 1991, el análisis de la desamortización eclesiástica en Segrero, Conventos, 1988, o el balance Balboa y Funes, "Tierra", 2001. De historia regional y local apenas hay investigaciones, véanse Venegas, "Acerca", 1995, y Bergad, Cuban, 1990.

${ }^{12}$ Dembicz, Plantaciones, 1989; Denslow, Sugar, 1987, y Edquist, Capitalism, 1985.
} 
han mejorado el conocimiento de las primeras y el más comprensivo, Entre haciendas y plantaciones, precisó de más de una década de trabajo en archivos para construir una base de datos de 276 ingenios.

Sabíamos que los ingenios cubanos elevaron rápidamente su oferta (de 7000 a 100000 toneladas) entre 1775 y 1830, aprovechando la coyuntura del mercado y las políticas de fomento, aunque también que estas no bastaron, como prueba su comparación con Puerto Rico, donde no tuvieron igual efecto. Sus factores productivos, por tanto, debían estar preparados para tal expansión cuando la revolución haitiana proveyó el que hasta entonces había escaseado, los esclavos, que aumentaron de 44000 a $300000,{ }^{13}$ pero hasta la publicación de Entre haciendas y plantaciones el tema no se había analizado pormenorizadamente. ${ }^{14}$

El libro empieza analizando cómo se financió el ingenio antes de su gran expansión. Muestra que aquel dispuso de crédito oficial gracias a los bienes desamortizados a la Iglesia -lo que además coadyuvó a liberalizar la tierra (pues desde hacía tiempo se estaban demoliendo vínculos, dividiéndose y arrendándose fincas) y a mejorar su explotación-, ${ }^{15}$ y que se invirtieron en él beneficios de la trata, la producción de tabaco o el comercio generados por la actividad del puerto habanero, donde se reunía la flota de Indias antes de regresar a España. Y a la disposición de capital contribuyó también el aumento del gasto público y el de los situados que remitía México para costear las defensas de Cuba, debido a las incesantes guerras en el Caribe desde la década de 1740, temas que han estudiado otros autores. ${ }^{16}$

Sabíamos que los ingenios cubanos mantuvieron su competitividad frente a los problemas que se presentaron con cambios tecnológicos y que ese modus operandi se estableció en el periodo en que iniciaron su gran expansión. ${ }^{17}$ Entre haciendas y plantaciones lo documenta, completa su conocimiento para la época previa a la abordada en El ingenio, si bien adolece en su análisis económico, carece de cálculos de costes y rendimientos -aunque aporta los datos para estimarlos- y de enfoque comparado y contextualizado en el mercado internacional; no obstante, eso lo solventa en parte otro estudio, que muestra que la citada expansión de la oferta azucarera en Cuba coincidió con su crisis en otras Antillas, donde se abolía la trata en 1808 y la esclavitud en 1838, gracias a que respondió a las dificul-

${ }^{13}$ Santamaría, "Azúcar”, 2006, pp. 167-181, y Fuente, "Sugar”, 2005, pp. 115-157.

${ }^{14}$ García-Rodríguez, Haciendas, 2009. Véanse también los adelantos de esa investigación en García-Rodríguez, Aventura, 2000, y Misticismo, 2000, y el estudio precedente en Tornero, Crecimiento, 1996.

${ }^{15}$ García, "Auge”, 1994, pp. 218-262.

${ }^{16}$ Kuethe, Cuba, 1986, y Vázquez y Santamaría, "Cuba”, 2012.

${ }^{17}$ Santamaría y García-Álvarez, Economía, 2004, pp. 123-125. 
tades de sus competidores mediante las referidas soluciones tecnológicas, empezando por el tendido de ferrocarriles, que permitieron compensar la escasez y carestía del trabajo. ${ }^{18}$

Entre haciendas y plantaciones, además, analiza el ingenio como complejo agroindustrial y su coordinación como clave de eficiencia, lo que junto a los costes de ajuste que eso implica sería una constante en su desarrollo. Así demuestra que la adopción de tecnologías de vapor no fue necesariamente más eficiente si había alternativas y no se asociaba con otras innovaciones en el resto de la cadena productiva. Y muy relevante, asimismo, es su conclusión de que, pese a lo dicho, no todo fue competitividad, y los hacendados también aprovecharon su posición socioeconómica para obtener ventajas y concesiones del Estado.

Desde esa perspectiva, la del azúcar y el poder, abunda otra obra, la dedicada a Arango, la figura más relevante de lo que sus editoras llaman "la invención de la Cuba azucarera", y que estudian a través de su contexto. ${ }^{19}$ La expansión de la oferta insular del dulce desde 1791 mediante la liberalización de la trata tuvo efectos más trascendentes: implicó redefinir la economía y la sociedad insulares y su vínculo colonial en torno al ingenio y la esclavitud. Naranjo sostiene que se impuso a otras alternativas porque con Arango se convirtió en un proyecto viable, y Piqueras sustenta que fue posible gracias a que la elite de hacendados, a la que el personaje representaba en la Corte española, conocía el interés existente por fomentar la economía cubana y había tejido una red de relaciones que le permitió aprovecharla en su beneficio mediante la elaboración de un plan, el Discurso sobre la agricultura, donde se exponía el modo de rentabilizar la ocasión que brindaba la revolución haitiana para expandir la producción de dulce con esclavos mediante políticas y la creación de instituciones que permitiesen su sostenimiento cuando retornase la normalidad. ${ }^{20}$

La viabilidad del proyecto de Arango, pues, radicó en su conocimiento de la oportunidad que brindaba el contexto, en su diagnóstico de las debilidades y las fortalezas para aprovecharlo y del posibilismo del compromiso requerido. Redefinir la sociedad, economía y pacto colonial en torno a una actividad productiva requería voluntad política del gobierno, pero también de quienes la ejercían. Tomich señala que desde la generación de hacendados a la que perteneció Arango, el ingenio se gestionó con métodos modernos y se impuso ese modus operandi que, como comentamos al hablar de Entre haciendas y plantaciones, se perpetuó después. Según Ferrer, para lograrlo se ayudaron de técnicos y empresarios huidos de Haití,

\footnotetext{
${ }^{18}$ Santamaría, "Islas", 2011, pp. 147-176.

${ }^{19}$ González-Ripoll y Álvarez, Francisco, 2009.

${ }^{20}$ Naranjo, “Cuba", 2009, pp. 27-40, y Piqueras, "Amigos”, 2009, pp. 151-166.
} 
pero también de un impulso científico y educativo sin parangón anterior en Cuba. ${ }^{21}$

En el sentido expuesto, Arango fue sobre todo un mediador entre intereses, y esa posición, su formación, capacidad y practicidad le permitieron formular propuestas adecuadas a su momento y tener éxito. ${ }^{22}$ Jonhson señala que tales intereses son difíciles de reducir a la dicotomía insular y peninsular con que suelen estudiarse, pues enfrentaron a un sector de la elite metropolitana que trató de desplazar a la cubana del poder colonial, con otro más liberal, integrado por esta y por españoles, y Vidal sostiene que su pugna se materializó en Cuba en las disputas entre el intendente y Arango (cuando este era ya síndico consular) y entre sus amigos y enemigos políticos, y si el segundo se impuso fue en dicho contexto de oportunidades para expandir la oferta azucarera y porque, según Opatrný, supo proponer una idea de patria integradora en la que la isla, siendo colonia, compartía con la metrópoli derechos concedidos por el régimen político. ${ }^{23}$

Comparando Brasil y Cuba, Bivar cree que la revolución haitiana obligó a redefinir sus economías esclavistas y vínculos coloniales para mantenerlos. Sin embargo, sólo se logró en Cuba, lo que facilitó el posibilismo de sus elites, la no polarización entre sus intereses y los metropolitanos, y que la mayoría albergase expectativas de beneficio preservando el statu quo. El estudio de González-Ripoll y Álvarez Cuartero no abunda suficiente en tal idea, pero sí otro que señala que el proyecto de Arango fue sobre todo institucional. El Consulado creado según su plan, la Sociedad Económica, de la que fue miembro, y la Intendencia, que tras ocuparla él sería siempre oficiada por cubanos, guiaron el progreso insular y permitieron a la oligarquía criolla participar en la toma de decisiones. ${ }^{24}$ Dicho punto de vista sitúa la redefinición del pacto colonial en la isla en la órbita de los estudios que revisan las independencias del resto de Hispanoamérica, según los cuales estas no fueron resultado de proyectos nacionales, sino del vacío de poder causado por la invasión francesa a España, y que en su ausencia se impusieron los propósitos de unas elites, que usualmente fueron las vinculadas al comercio externo, menos castigado por las guerras de emancipación y ulteriores. ${ }^{25}$ En Cuba su elite había visto satisfechas razonablemente sus aspiraciones dos décadas antes.

\footnotetext{
${ }^{21}$ Tomich, "Invention", 2009, pp. 133-150; Ferrer, "Mundo", 2009, pp. 105-116, y GarcíaGonzález, "Francisco", 2009, pp. 301-324.

${ }^{22}$ Gonçalvès, "Francisco", 2009, pp. 213-228.

${ }^{23}$ Johnson, “Autority”, 2009, pp. 193-212; Vidal, “Coyunturas”, 2009, pp. 117-132, y Opatrný, "Patria", 2009, pp. 167-178.

${ }^{24}$ Bivar, “Comparando”, 2009, pp. 67-84, y Santamaría y Vázquez, Discurso, 2014.

${ }^{25}$ Bandieri, Historia, 2010.
} 
La reforma colonial, señala Vázquez Cienfuegos, supuso además que la elite habanera impusiese su proyecto en Cuba. Entre los alternativos que refería Naranjo estaba el de la oligarquía oriental, que analizan Irisarri o Belmonte, ${ }^{26}$ respaldado, según Fernández Mellén, por parte del clero, algún gobernador e intelectuales defensores de una economía más diversificada, campesina y blanca, o el antiguo predominio comercial del tabaco, cuyo reemplazo por el azúcar-sostiene Sanz- modificó la sociedad y dio lugar a una nueva hegemonía, la de la sacaracrocia. ${ }^{27}$ Pero entonces otra exportación, la cafetalera, tan expansiva como la azucarera, progresaba en la mitad este insular; además, tanto el crecimiento demográfico como el fomento a la inmigración no ofrecían a corto plazo el trabajo que precisaba la agricultura comercial. ${ }^{28}$

La reforma colonial se materializó en la liberalización del comercio de Cuba y la fiscalización de sus rentas por la metrópoli. Fernández de Pinedo aporta nuevos datos y análisis económicos que avalan esa tesis y otro estudio explora cómo se efectuó el tránsito en la isla, de receptora de situados del imperio a contribuyente del erario español. Compara su caso y el mexicano corroborando que la institucionalización, autonomía y practicidad de su gobierno, la política de fomento y la participación de sus elites en las decisiones ayudan a explicar su no independencia. ${ }^{29}$ Kuethe decía que la razón eran los situados, pero entonces hacía años que no se recibían, y Gonçalvès examina dicha oligarquía con métodos prosopográficos, su genealogía, títulos, cargos militares y funcionariales que fue adquiriendo, y afirma que formó un sólido grupo, reforzado tras la conquista británica de La Habana en 1762, cuando se solicitó su apoyo para acometer reformas. $\mathrm{Y}$ por iguales causas sostiene que su desplazamiento posterior del poder se debió a la pérdida de su consistencia grupal, fruto de su endogamia y gasto suntuario, en detrimento de la inversión productiva que la caracterizó antes. Aparte del tratamiento novedoso del tema, esto confirma la tesis de Kuethe sobre que la refundación del pacto colonial fue negociada con la elite criolla, aunque sin responder la objeción que planteara Amores acerca de que cuando aquella obtuvo más concesiones su capacidad económica y aportación fiscal eran aún escasas. ${ }^{30}$

En suma, la reforma colonial reforzó la hegemonía de La Habana en Cuba. El ingenio se desarrolló inicialmente en su hinterland y con el ferrocarril se extendió por el oeste, lo que agravó los desequilibrios socioterrito-

${ }^{26}$ Vázquez, Difíciles, 2008; Belmonte, Ser, 2011, e Irisarri, Oriente, 2003.

${ }^{27}$ Sanz, "Arango", 2009, y Fernández, Iglesia, 2013.

${ }^{28}$ Santamaría y García-Álvarez, Economía, 2004, p. 128.

${ }^{29}$ Fernández de Pinedo, Comercio, 2003, y Vázquez y Santamaría, "Cuba”, 2012.

${ }^{30}$ Kuethe, "Situado", 2005, pp. 201-218; Gonçalvès, Planteur, 2008, y Amores, "Elites", 2005, pp. 189-197. 
riales y tuvo otros efectos. Funes analiza la deforestación que ya sufrieran otras Antillas y testimonia su origen en la imposición del proyecto de los hacendados. El desmonte proveyó combustible y tierra a sus plantaciones y facilitó la extensión espacial y productiva de estas. Moreno Fraginals lo había investigado, pero Funes desborda el sesgo cronológico que aquel improntó en la historiografía, examina el periodo 1492-1927, y aplica a los estudios cubanos métodos de la historia ambiental y los introduce en sus debates. $^{31}$

Otro componente de la reforma colonial lo estudia Tomich con su conocida tesis de que se efectuó en interacción con una reexpansión de la trata que conceptualiza como second slavery y que se correspondió con el reemplazo del liderazgo comercial azucarero anglo-francés por el español. Esa tesis refuta la contraposición entre modernización y esclavitud y tiene relevantes implicaciones metodológicas, pues invita a analizar el tema en el contexto de los intercambios en el espacio atlántico, pero también con enfoques comparados y microhistóricos capaces de explorar la adecuación y estrategias de los actores implicados frente a los referidos cambios. ${ }^{32}$

\section{HISTORIA REGIONAL Y LOCAL, EDICIONES Y COMPENDIOS. NUEVOS MÉTODOS Y FUENTES}

Muchos trabajos regionales y locales, y con fuentes locales, otro déficit de la historiografía tradicional, desbordan también su cronología habitual, poco útil para analizar espacios inusuales en ella y procesos distintos a los de toda Cuba. Aunque señalamos que era imposible abordar aquí su temática, debemos mencionar los estudios de Pérez y Meriño sobre las relaciones entre esclavos y con sus amos, pioneros en la aplicación a la isla de la microhistoria y los new cultural studies, como los de Martínez et $a l$, que exploran las edificaciones azucareras, la centralización en la zona de Cienfuegos, la subsistencia de los africanos en un ingenio o los factores económicos en la construcción regional. ${ }^{33}$ Venegas es quien ha promocionado más las investigaciones con tal enfoque, junto con Venegas Fornías, cuya Cuba y sus pueblos lo enlaza con las pesquisas acerca del modo en que se fue inventado el país mediante el empleo de herramientas geodemográficas y cartográficas. ${ }^{34}$

${ }^{31}$ Funes, Rainforest, 2008.

${ }^{32}$ Tomich, Through, 2004, y Zeuske y Tomich, "Second", 2009.

${ }^{33}$ Pérez y Meriño, Esclavitud, 2008; Martínez et al., Espacios, 2001; García y Cuétara, "Testimonios", 2001, pp. 128-138; Iglesias, "Concentración”, 2001, pp. 85-106, y Sartorius, "Conucos", 2001, pp. 108-127.

${ }^{34}$ Venegas, "Formación”, 2001, pp. 75-84, y Región, 2001, y Venegas-Fornías, Cuba, 2001. 
Toda la historia regional y local de Cuba suele abordar entre sus temas el ingenio, pero hay estudios más específicos sobre él en Guantánamo, Media Luna ${ }^{35}$ y sobre todo en Trinidad. Aprovechando la declaración de la villa como patrimonio de la humanidad y el valor turístico y natural de su valle, preservado gracias a las mejores condiciones de otros lugares para la expansión de la plantación que permitió el ferrocarril desde la década de 1850 , se han realizado trabajos pioneros en la aplicación de métodos informáticos, artísticos y patrimoniales y de arqueología industrial. ${ }^{36}$

Trinitario era Cantero, autor de una obra excelente por sus litografías y estudio de los ingenios cubanos en 1856-1857. Entonces las dificultades de la trata, tras la abolición en Gran Bretaña, elevaba sus costes, y el crecimiento de la oferta de azúcar de remolacha en Europa, protegida en sus mercados, reducía los precios, situación que aquellos afrontaron con ferrocarriles, que ampliaron el área de cultivo de la caña, y adoptando evaporadores al vacío, que permitían moler más gramínea y extraer más azúcar de ella. Una reedición reciente del libro incluye análisis de dichos procesos, los censos de ingenios de 1860 y 1877, básicos para examinarlos, y es ejemplo de otra característica de la actual historiografía regional y local de Cuba, que suele abordarse mediante estudios de casos, publicación crítica de fuentes y elaboración de repertorios documentales y pequeños ensayos debido a la importancia para ella de los datos censales y noticiosos y de trabajos que sinteticen sus aportaciones. ${ }^{37}$

La síntesis de la información sobre ingenios se ha plasmado en repertorios acerca de Matanzas o Cienfuegos, que fue su principal área de expansión desde 1850, aunque la villa se creaba en 1818 como una de esas alternativas de colonización blanca y agricultura diversificada referidas por Naranjo, ${ }^{38}$ por lo que su metamorfosis ilustra el modo en que se extendió en Cuba el proyecto azucarero. El tren llegaba a ella en 1851 y diez años después producía 10\% del dulce insular. Un libro analiza el proceso y, no obstante que se limita al periodo esclavista, lo hace con fuentes locales, con las que prueba que se llevaron a la zona muchos esclavos de Oriente, ociosos por la crisis del cultivo cafetalero en la región, o que la elite habanera invirtió enseguida en ella, pero la provincial asumió pronto el control de su economía. Documenta la obra, además, que los ingenios cienfuegue-

${ }^{35}$ Sánchez, Azúcar, 2003, y Alarcón, Historia, 2002.

${ }^{36}$ López et al., Trinidad, 2003; Venegas, Trinidad, 2006; Quintero y Guerrero, Reconstrucción, 2007; Chaviano, "Trinidad", 2012; Chaviano y Echenagusía, "Guaimaro", 2009, pp. 50-55, y "Valle", 2009.

${ }^{37}$ Cantero, Ingenios, 2005. Páginas electrónicas como $<$ www.ecured.cu $>$ o $<$ www.monografias.com $>$ incluyen mucha información y estudios sobre ingenios, por ejemplo García y Fernández, "Industria", 2013, y Suárez, "Reseña", 2009. 85-122.

${ }^{38}$ Perret, Azúcar, 2008; Lapique y Arias, Cienfuegos, 2012, y Naranjo, "Temor", 2002, pp. 
ros fueron más grandes y avanzados en tecnología que los de Matanzas y La Habana, debido a su desarrollo más tardío, que su expansión fue a expensas de las demás actividades agropecuarias, reproduciendo a escala regional lo que había ocurrido en otras partes de Cuba, y que al igual que en ellas, los que se modernizaron sobrevivieron a la guerra de 1868-1878 y al inicio entonces del proceso abolicionista. Y esa aportación del libro sería poco novedosa si no fuese porque muestra cómo se financió su transformación, gracias al capital acumulado por la elite local. ${ }^{39}$

El centro de Cuba, donde se halla Cienfuegos, es objeto de otra investigación que aplica métodos geocartográficos y lo califica de último escalón del ingenio esclavista, pues en el siglo XIX no se logró unir por ferrocarril el oeste insular con el este. Además estudia su elite, que nutrió el liderazgo mambí y la alta clase dirigente republicana, y aunque el análisis de sus negocios se limita al periodo esclavista, corrobora los cambios en la oligarquía insular con la expansión del ingenio que apuntaban Cantero o García Martínez y cuyo principal exponente fue Julián de Zulueta. ${ }^{40}$

Zulueta dispone de una de las pocas biografías de la historiografía económica cubana. El libro arroja luces sobre sus vínculos políticos, familiares y de paisanaje -era inmigrante español-, su dedicación original a la trata y como miembro del Cabildo de La Habana, especialmente en su modernización urbana, pero no analiza la interacción entre tales actividades, donde radica su enjundia, la razón por la que fue el hacendado más importante de su época, pionero de la completa mecanización del ingenio y dueño del primero dotado de ferrocarril industrial, el central Álava, tipo de instalación que acabaría reemplazando a la plantación esclavista. ${ }^{41}$

\section{INGENIOS POR CENTRALES; ESCLAVOS POR COLONOS.} TECNOLOGÍA Y ESCLAVITUD

El caso del central Álava ratifica la tesis reciente que prueba, usando métodos cuantitativos, que tras iniciarse la abolición, los ingenios cubanos siguieron usando esclavos mientras pudieron, compensaron tecnológicamente su escasez y carestía y no los reemplazaron por asalariados, sino mediante la reorganización que dejaba la oferta cañera en manos de colonos, lo que refuta el modo en que examinaba el problema, ${ }^{42}$ comparando la rentabilidad de la esclavitud y el trabajo remunerado, contrafactual

${ }^{39}$ García, Esclavitud, 2008.

${ }^{40}$ González, Último, 2003.

${ }^{41}$ Marrero, Julián, 2008. Sobre otras fortunas de inmigrantes españoles y la transferencia de capitales véanse Rodrigo, Marqueses, 2001, y "Trasvase", 2009, pp. 127-149.

${ }^{42}$ García-Mora y Santamaría, "Esclavos", 2002, pp. 252-271. 
inadecuado en un mercado laboral que no era libre. ${ }^{43}$ Un estudio de dos plantaciones cienfuegueras corrobora dicha tesis e ilustra los avances en la investigación sobre formación de fortunas, redes empresariales y transferencia de capitales entre Cuba y España, pues muestra que pudo invertirse y fluir de metrópoli a colonia en función del beneficio esperado, que en el caso de la transformación de los ingenios a finales del siglo XIX se consideró mejor que el de otras alternativas de inversión. ${ }^{44}$

Los estudios anteriores están editados en un libro que alberga otros igualmente ilustrativos de los avances historiográficos: análisis del impacto ambiental de los ingenios, la relación entre tecnología, mano de obra e inmigración o la esclavitud como un bien de capital. ${ }^{45}$ Vinculado con ello, Balboa estudia los problemas demográficos y laborales de Cuba entre 1878-1898 examinando los proyectos de poblamiento civiles y militares que se desarrollaron. Los últimos intentaron sin éxito que los soldados españoles se quedasen en la isla tras licenciarse para españolizarla y aumentar su masa trabajadora que, según la autora, no fue tan escasa como se pensaba, aunque la afirmación no es corroborada por los censos y además omite que hubo dificultades de movilización del mercado trabajo y desincentivos para nutrirlo con inmigrantes mientras se rigió por relaciones esclavistas. ${ }^{46}$

En síntesis, la respuesta tecnológica a los problemas es el principal continuum de la historia del ingenio en Cuba desde 1790 y sigue analizándose en relación con la esclavitud, pero sin suponer una contradicción intrínseca y con enfoques capaces de abarcarlo en toda su complejidad. Curry-Machado estudia las redes migratorias de técnicos llegados con la maquinaria y señala que, por ser extranjeros, británicos generalmente, fueron privilegiados en un sistema de trabajo esclavo, pero también chivos expiatorios cuando surgieron problemas en él, tras la abolición en Inglaterra y las revueltas negras acaecidas en la década de 1840. Fernández de Pinedo compara Java y Cuba y dice que las plusvalías del negocio azucarero se sustentaron en regímenes laborales compulsivos, en el empleo forzado de nativos y en la trata negrera respectivamente, prácticas prohibidas reiteradamente, pero que subsistieron todo el siglo XIX debido a que también lo hicieron sus causas: la caña se corta manualmente y precisa muchos brazos, y la producción de dulce devengaba elevadas rentas fiscales, en las que se basó el vínculo colonial en ambas islas. Esa tesis no contradice que iguales factores explicasen los avances técnicos en los ingenios cubanos, pues fueron los que permitieron mantener la esclavitud a partir de los años

${ }^{43}$ Moreno-Fraginals et al., Slavery, 1985, y Bergad, Cuban, 1990.

${ }^{44}$ Rodrigo, "Ingenios", 2002, pp. 271-291.

${ }^{45}$ Funes, "Tierras", 2002, pp. 186-213; García, "Tecnología”, 2002, pp. 214-251; Piqueras, "Capital”, 2002, pp. 93-114, e Iglesias, "Cuba“, 2002, pp. 76-92.

${ }^{46}$ Balboa, Brazos, 2002. 
cuarenta, pese a sus dificultades. De hecho su autora analiza las condiciones en que se dieron y, en sintonía con los estudios sobre la contribución socioeconómica de las elites criollas, prueba que ellas administraron las instituciones que incentivaron la innovación y controlaron las patentes, lo que facilitó su participación en las redes de transferencia tecnológica internacionales. ${ }^{47}$

\section{CUBA AZUCARERA EN PERSPECTIVA COMPARADA. LA ESPECIALIZACIÓN ECONÓMICA Y SUS EFECTOS}

Como la mayoría de los analizados hasta ahora, los estudios recientes sobre otros temas abordan la economía y sociedad cubanas con enfoques más complejos que los tradicionales, tienen en consideración las novedades historiográficas, participan en los debates internacionales y han reforzado su presencia en obras colectivas dedicadas a problemas económicos, de la producción y el comercio de materias primas o la industria azucarera trasnacionales, en el espacio atlántico, americano o caribeño. ${ }^{48}$

Esos estudios analizan comparativamente la refundación del colonialismo español en Cuba en torno al proyecto azucarero y suelen destacar que sus diferencias con el británico, por las que había sido tildado de anacrónico, fueron coherentes, pues también lo eran la situación de la metrópoli y su isla y, por tanto, la razón de su éxito y perdurabilidad. ${ }^{49} \mathrm{Al}$ carecer España de mercado para la producción antillana, se permitió su libre comercio y se extrajeron rentas del crecimiento resultante mediante mecanismos fiscales. ${ }^{50}$

Enfoques comparados confirman la idea anterior. La abolición en Gran Bretaña perjudicó la oferta azucarera caribeña, incluida la de Puerto Rico, la otra Antilla española, pero la de Cuba inició su fase más expansiva gracias al ferrocarril y a cambios tecnológicos que desvincularon su incremento y el del número de esclavos, compensaron el encarecimiento de los

\footnotetext{
${ }^{47}$ Curry-Machado, "Azúcar”, 2007, pp. 116-138, y Cuban, 2011; Fernández de Pinedo, "Islas“, 2006, pp. 137-155, y Fernández de Pinedo et al., Colonial, 2011.

${ }_{48}$ Véanse História, 2002; Swartz, Tropical, 2005; Santamaría y García-Álvarez (coords.), Industria, 2005; Açucar, 2005; Luxán y Viña, Azúcar, 2006; Piqueras, Azúcar, 2002, y Trabajo, 2009; Haber, Political, 2000; Lavalle, Naranjo y Santamaría, América, 2002; Opatrný, Nación, 2003, y Cambios, 2006; Piqueras, Antillas, 2005; Navarro, Elites, 2005; Opatrný y Naranjo, Caribe, 2006; Roldán, Haciendas, 2007; Naranjo, Historia, 2009; Bértola y Gerchunoff, Institucionalidad, 2011; Yáñez y Carreras, Economies, 2012, y el análisis de los debates internacionales Santamaría, "Temas", 2006.

${ }^{49}$ Zeuske, "Cuba", 2006, pp. 11-27.

${ }^{50}$ Fernández de Pinedo, Comercio, 2003; Santamaría y García-Álvarez, Economía, 2004, y Santamaría, "Dos", 2011, pp. 147-176.
} 
africanos y dieron lugar al modelo más complejo de plantación esclavista. Además, estudios sobre la renta, los precios o los salarios muestran que el resultado fue un crecimiento similar o superior al de las principales economías latinoamericanas y europeas y evidencian que la especialización productiva insular no fue un proceso lineal y que su oferta fue más diversificada de lo que se pensaba. En definitiva recuperan la reflexión de Le Riverend e indican que incluso cuando la escasez y la carestía laboral acrecentaron la concentración de recursos en los ingenios en detrimento de otras actividades, gracias a su ventaja comparativa estos siguieron generando externalidades que favorecieron el desarrollo de cultivos, industrias y servicios destinados a abastecer su demanda y el consumo de la creciente población urbana y por cuya dedicación y tamaño se parecieron igualmente a los de las grandes economías latinoamericanas. ${ }^{51}$

La economía que se configuró en Cuba fue relativamente diversificada, pero complementaria del sector externo, cuya expansión perjudicó a las actividades que competían por el escaso trabajo, mejores tierras y capital. Sin embargo, las redes de negocio, servicios e infraestructuras favorecieron a otras que, normalmente, crecieron en tiempos de auge del sector exportador, pero carecieron de capacidad para compensar sus crisis. Confirman esa tesis estudios recientes acerca de la industria y la agricultura en el oeste insular o la compilación Más allá del azúcar, dedicadas al periodo posesclavista. ${ }^{52}$ La época anterior goza de un análisis general con estimaciones cuantitativas o investigaciones sobre el impacto del ingenio en los cultivos de subsistencia. Además la historiografía regional suele tratar el tema, y un artículo de Venegas Fornías contabiliza y estudia los sitios de labor y estancias en el siglo XIX e insiste en los referidos efectos espaciales de la especialización económica, destacando las diferencias entre el oeste y el este de Cuba, en muchas de cuyas regiones la caña no tuvo ventaja comparativa y se desarrollaron otras actividades que, sin embargo, comúnmente acabaron sucumbiendo a la concentración de los recursos en la industria azucarera. ${ }^{53}$

Varias investigaciones estudian diversos aspectos de la tierra en Cuba o sus regiones ${ }^{54}$ pero siguen sin analizarse la desamortización civil o el

${ }^{51}$ Lavalle, Naranjo y Santamaría, América, 2002; Santamaría y García-Álvarez, Economía, 2004; Santamaría, "Precios", 2000, pp. 339-376, "Estimaciones", 2003, pp. 113-133, y "Dos", 2011, pp. 147-176.

${ }^{52}$ Santamaría y Naranjo, Más, 2009; Fernández, Cuba, 2005; Marqués, Industrias, 2006, quien analiza también la industria de derivados del azúcar, que sólo ha merecido otro estudio, Bonera, Historia, 2005.

${ }^{53}$ Santamaría, "Márgenes”, 2002, pp. 103-132; Curry-Machado, “Cane’s”, 2013, y VenegasFornías, "Estancias", 2001, pp. 1-26.

${ }^{54}$ Balboa, "Guantánamo", 2003, pp. 123-141, y “Asalto", 2006, pp. 55-78; Sanz, “Concesión”, 2005, pp. 247-273, y Balboa y Funes, “Tierra”, 2001, pp. 89-104. 
suelo como factor productivo, e igual ocurre con el trabajo, sobre todo en el periodo posabolicionista. Sin embargo, sí se ha seguido profundizando en el efecto medioambiental del ingenio. Aparte de los referidos estudios de Funes, Jofre explora su relación con la transición energética en la economía insular, el aprovechamiento óptimo de los recursos y sus resultados en el crecimiento y Yáñez compara su caso con el de Chile. ${ }^{55}$

Algunos estudios, además, han ampliado el espectro de la historiografía sobre el azúcar a temas socioantropológicos, como la construcción de la historia, la cultura o la formación de identidades en perspectiva caribeña y comparada, aunque en general suelen abordarlos desde el punto de vista de esos modelos alternativos y complementarios de sociedad referidos por Naranjo, que convivieron y coexistieron en la Cuba azucarera, más que en el sentido de los enfoques subalternos y excluyentes del análisis histórico tradicional de los new cultural studies, los estudios poscoloniales y microhistóricos. ${ }^{56}$

La progresiva especialización económica de Cuba, sus otredades productivas, laborales, socioculturales, las estrategias cambiantes de sus actores, son los espacios en los que acaban o acabarán coincidiendo los estudios focalizados en el ingenio y sus esclavos, predominantes por la importancia en la isla de la industria azucarera, la población de color y el mestizaje. Sin embargo eso no debe excluir seguir realizando investigaciones más convencionales, pues aún sabemos poco de las actividades menos vinculadas con las exportaciones, incluso de algunas afines, y aunque recientemente se ha mejorado sustancialmente su conocimiento, se requieren muchos más análisis para tener una idea precisa de los mismos y construir un discurso histórico más integral y complejo.

Los ferrocarriles de Cuba cuentan con nuevos estudios, y aunque los industriales siguen sin investigación, se exploran aspectos poco conocidos, líneas, regiones, las locomotoras de vapor, aprovechando su actual rescate con fines turísticos y patrimoniales. ${ }^{57}$ Respecto al sector financiero, un libro lo examina comparativamente en el contexto del ultramar español $\mathrm{y}$, con un punto de vista similar, otro aborda las cajas de ahorro y muestra que si bien canalizaron el ahorro popular, igualmente ilustran la citada complementariedad de todos los sectores económicos respecto del exter-

${ }^{55}$ Funes, Rainforest, 2008; Funes y Tomich, "Naturaleza", 2009, pp. 75-120; Jofre, "Sugar", 2012, pp. 201-226, y Yáñez, "Economic”, 2012, pp. 133-157.

56 Seminario, 2005; Martínez-Fernández, Frontier, 2011, y Curry-Machado, "Cane’s”, 2013.

${ }^{57}$ Véanse Rogers, Sugar, 2003; Iglesias, Ferrocarriles, 2003, y Trocha, 2009, edición ilustrativa de los avances recientes en la investigación, y ejemplo de los muchos trabajos que es posible encontrar en Internet, Morrison, "Hershey", 2002. 
no, pues la establecida en La Habana sucumbió en la crisis azucarera de $1883-1884 .^{58}$

Los bancos cuentan también con un compendio como los editados sobre ingenios en varias regiones de Cuba. Además un estudio de Fernández sobre el mercado de capital entre 1878-1895 destaca que sus limitaciones obligaron a depender de recursos exteriores y agravaron la concentración de los recursos en el sector externo. Sin embargo, esto parece coherente con las condiciones coloniales de la isla y su estructura de oferta, que Roldán analiza en el caso del Banco Español, mostrando que, en efecto, priorizó los negocios comerciales y tuvo un carácter semipúblico reforzado tras la guerra de $1868-1878,{ }^{59}$ pero la financiación de la deuda contraída entonces, del déficit estatal y la acuñación de billetes y la falta de políticas de fomento pesaron más en las dificultades que tuvieron los ingenios para costear su transformación y en la insuficiente movilización de los factores productivos que los defectos del sistema financiero.

\section{Del ingenio al Central. AzÚCAR y Fin del COlOnialismo ESPAÑOL}

El proceso más ignoto de la historia del ingenio en Cuba es la centralización con la que completó su mecanización, afrontó la abolición, acudió a la inmigración como recurso laboral y descentralizó su oferta de caña. La propiedad de la tierra o su usufructo eran más atractivas para ex esclavos o inmigrantes que emplearse por un salario, y mediante el llamado colonato los centrales externalizaron parte de los costes del trabajo, escaso y difícil de movilizar. El tema cuenta con estudios recientes, pero precisa aún más y tropieza con la dificultad de encontrar fuentes y la necesidad de abordar muchos estudios de casos.

Fruto de los procesos referidos en Cuba se erigieron los centrales más grandes del orbe, con extensos latifundios y ferrocarriles privados, pues mediante la propiedad del suelo y los transportes procuraron establecer condiciones de monopsonio sobre los colonos para evitar que fijasen el precio de la caña, efecto colateral de la descentralización de su oferta. Junto a la adquisición de tecnología esto requirió grandes inversiones, que sumadas a la devastación causada por la guerra de Independencia, provocaron el cierre de $75 \%$ de los ingenios existentes en $1895 .{ }^{60} \mathrm{Su}$ transformación en colonias de otros cercanos elevó el volumen de materia prima disponible, lo que explica que adoptasen tecnologías destinadas a proce-

\footnotetext{
${ }^{58}$ Roldán, Haciendas, 2008, y Comín et al., Cajas, 2011.

${ }^{59}$ Tablada y Castelló, Historia, 2008; Fernández, Encumbered, 2002, y Roldán, Banca, 2004.

${ }^{60}$ Iglesias, Economía, 2005.
} 
sarla en masa y a aumentar su rendimiento industrial, pero no el agrario, ya que la tierra y la caña eran los recursos relativamente más abundantes.

Obras recientes sobre el siglo XX abordan la centralización con métodos econométricos y permiten conocer con precisión sus resultados, ${ }^{61}$ pero sabemos muy poco de su proceso en el XIX. La información desagregada disponible impide contar con una muestra suficiente para estudiarlo y obliga a realizar más investigaciones regionales y de casos, pues el único trabajo existente al respecto lo aborda con fuentes indirectas y agregadas y, aparte de que no las homogeniza ni las analiza económicamente, sólo logra develar sus características generales. ${ }^{62}$

Algunas obras referidas mejoran el conocimiento de varios temas -tierra, finanzas, inmigración, tecnología o ferrocarriles- en relación con el proceso de centralización. Sin embargo, carecemos de investigaciones sobre la migración estacional llegada a Cuba para trabajar en la zafra (el clima sólo permite realizarla entre noviembre y junio). El colonato cuenta con un nuevo estudio general con fuentes indirectas y déficits similares al de Iglesias, dos trabajos más que comparan el sistema en empresas de Estados Unidos en el Caribe hispano y su uso simbólico en la construcción de la identidad nacional, y con un artículo de Dye que prueba su racionalidad en función de las alternativas tecnológicas y laborales de los centrales y de su dotación de factores. Finalmente McGillivray indaga en las comunidades campesinas de dos ingenios en el centro y este insular, y aunque sólo trata brevemente el siglo XIX es valioso por sus fuentes locales, su metodología y la exploración de temas novedosos como las relaciones entre hacendados, colonos y trabajadores y el modo en que se vieron afectados y participaron en las transformaciones sociopolíticas de la isla. ${ }^{63}$

El complejo proceso de transformación laboral, tecnológica y organizativa de los ingenios cubanos entre 1870-1900 es aún muy poco conocido. Las obras de Ayala o Dye priorizan el siglo XX, pero contribuyen al estudio de otro aspecto, el empresarial, y desde puntos de vista muy distintos. El primero discute la extrapolación a las Antillas hispanas de la teoría que considera la plantación como eje analítico de la historia caribeña y subraya que su invasión por parte de Estados Unidos coincidió con la integración vertical de las refinerías azucareras del país y de sus centrales en dichas Antillas, y sostiene que ese sugar trust fue resultado de la lucha por la hegemonía internacional en el sector mediante el uso del poder que confería su

${ }^{61}$ Ayala, American, 1999; Dye, Cuban, 1999; Santamaría, Azúcar, 2002, y Zanetti, Economía, 2009.

${ }^{62}$ Iglesias, Ingenio, 1999.

${ }^{63}$ González, "Esclavo", 2005, pp. 57-64; Ayala, American, 1999; Santamaría, "Economías", 2006, pp. 167-180; Dye, "Privately”, 2000, pp. 219-272, y McGillivray, Blazing, 2009. 
pertenencia a una potencia en expansión, más que respuesta a razones de eficiencia y organizativas para reducir los costes de transacción.

El sugar trust, empero, no tuvo una composición homogénea y sin cambios, y los hacendados cubanos participaron en él, incluso en posición prominente. Dos libros recientes lo confirman y discuten el enfoque imperialista de Ayala. Una biografía de Miguel A. Falla, sucesor de uno de aquellos hacendados, prueba que el gobierno de Estados Unidos incentivó a los empresarios españoles, que habían tejido sólidas redes de negocio en el mercado estadunidense, a quedarse en Cuba después de 1898, idea que corrobora una obra sobre Manuel Rionda, inmigrante asturiano en la isla residente en Nueva York, que fue el principal emprendedor azucarero de su época y hombre puente entre los distintos intereses transnacionales implicados en la producción y la comercialización del dulce. ${ }^{64}$

Con similar perspectiva Dye muestra que las empresas azucareras estadunidenses en Cuba no superaron en tecnología, eficiencia o acceso al crédito a las insulares, lo que dependió de sus estrategias de localización e inversión para optimizar las condiciones y dotación de recursos con las que operaban. Además, como los referidos estudios sobre el siglo XIX, el autor prueba que la transferencia tecnológica en la industria del dulce no fluyó del centro económico mundial a la periferia, sino en ambos sentidos. ${ }^{65}$

Las tesis de Dye, por otro lado, sintonizan con los estudios de la relación entre el crecimiento de la industria azucarera y el fin del colonialismo español en Cuba. Tras el surgimiento de la amenaza independentista, vinculada a sus desequilibrios económicos y territoriales, pues la guerra de 1868-1878 se circunscribió a su mitad este, y la supresión de la esclavitud, del proyecto azucarero con que se refundaba aquel en 1790, quedaban los vínculos entre las elites criollas y de la metrópoli como contrapeso de las rentas que esta extraía de la isla. Sin embargo, habían surgido elementos nuevos. Las exportaciones insulares de dulce se concentraban en Estados Unidos, país que desde 1880 adquiría más de $80 \%$ de ellas, y la migración en masa que llegó a la Gran Antilla después de la abolición de la esclavitud reforzaba la españolización de su sociedad.

Estudios recientes señalan que las razones económicas de la crisis del colonialismo español en Cuba fueron implícitas. El esfuerzo de transformación de los ingenios requería disponer de mercado, pues su rentabilidad dependía de poder producir en masa. El mercado era Estados Unidos, que establecía una política proteccionista y de reciprocidad consistente en reducir los aranceles a las mercancías procedentes de lugares que otorgasen un tratamiento similar a las suyas, lo que ya en la década de 1880

\footnotetext{
${ }^{64}$ Echevarría, Captains, 2002, y McAvoy, Sugar, 2003.

${ }^{65}$ Dye, Cuban, 1999.
} 
provocaba en la isla que sus elites se uniesen, dejando al margen otras diferencias, en demanda de soluciones al problema. ${ }^{66}$

La respuesta política española fue coherente con sus circunstancias. Priorizó la firma de tratados con Estados Unidos para facilitar la venta del azúcar de Cuba. Piqueras analiza los mecanismos de acción colectiva implicados y muestra que el resultado fue el reparto del mercado insular entre las importaciones estadunidenses y metropolitanas, lo que favorecía a estas últimas, pues se aumentó su protección arancelaria y se incrementó la extracción fiscal de renta de la colonia, que dependía de los ingresos aduaneros. ${ }^{67}$ Sin embargo, tal solución agravaba las causas de los problemas, pues sancionaba la progresiva vinculación de las economías cubana y estadunidense y otorgaba al gobierno de un país extranjero capacidad de decisión sobre la principal garantía de crecimiento y estabilidad de la isla.

En 1895 el gobierno de Estados Unidos decidía no renovar el tratado con España y estallaba una nueva guerra de Independencia en Cuba. Quizá no hubo relación directa entre ambos hechos y, como dice Piqueras, el dinamismo de la sociedad insular había desbordado al de la política, pues tras el anterior conflicto se promovían reformas que no llegaron a completarse y a culminar la idea de los hacendados de finales del siglo XIX de una patria común sustentada en el régimen político, y parece que en circunstancias tales las elites criollas carecían ya de las expectativas razonables de progreso de sus negocios dentro del sistema colonial en el que operaban como único contrapeso de su falta de poder. ${ }^{68}$

\section{CONCLUSIÓN}

Estudios recientes han mejorado notablemente el conocimiento de la industria azucarera y la economía de Cuba entre 1765 y 1898 con nuevos métodos, fuentes y enfoques regionales, casuísticos, comparados y transdiciplinares, y su participación en los debates internacionales, superando sesgos y tópicos analíticos heredados y abordando temas y tiempos poco investigados. Han revisado la existencia de una contradicción intrínseca entre esclavitud y tecnología y probado que los hacendados insulares emplearon esta última para preservar la primera, participaron en la generación y trasferencia de conocimiento, no fueron receptores pasivos, y en la formación de las redes comerciales y financieras de su negocio. Asimismo

66 Zanetti, Comercio, 1998.

${ }^{67}$ Santamaría y García-Álvarez, Economía, 2004, p. 348, y Piqueras, "Relaciones”, 2002, pp. 77-101.

${ }^{68}$ Piqueras, Cuba, 2003, y Santamaría y García-Álvarez, Economía, 2004. 
han examinado la refundación del colonialismo español en la isla hacia 1790 y mostrado su consistencia, que se había cuestionado por sus diferencias con el británico, sin considerar que sus circunstancias fueron también muy diferentes.

Las nuevas perspectivas de investigación, sin embargo, han aumentado la necesidad de análisis acerca de distintos temas poco conocidos de la industria azucarera y su impacto ecológico, en la sociedad o en la economía de Cuba. Estudios recientes muestran que el principal problema de esta última no fue su falta de diversificación, sino la complementariedad de toda su estructura respecto al sector externo azucarero y sus desequilibrios socioterritoriales, que se agravaron al limitarse la extensión del ingenio en el siglo XIX al oeste insular, lo que precisa realizar más investigaciones acerca de su oferta agroindustrial, servicios, infraestructuras o mercado laboral, generales y a escala regional, que han comenzado a hacerse, aunque aún quedan aspectos que no se han abordado, como los ferrocarriles industriales de los centrales o del flujo migratorio estacional que estos recibieron tras la abolición.

El inicio de la gran expansión de la oferta azucarera de Cuba a finales del siglo XVIII y su relación con la refundación de su pacto colonial con España en torno a ella se ha revisado también en el contexto de los procesos de independencia hispanoamericanos y de las razones por las que no cuajaron en la isla. No sucede igual con el otro periodo de gran transformación del ingenio, el final del siglo XIX, y su relación con el fin de dicho sistema colonial. La causa es su complejidad y la escasez de fuentes y que exige un esfuerzo de investigación que aún está por hacerse, aunque cuenta con la ayuda de que los estudios sobre el siglo XX han precisado sus rasgos generales y racionalidad económica y con que varios trabajos han mejorado sensiblemente el conocimiento de aspectos parciales o vinculados a dicha transformación.

\section{BibLIOGRAFÍA}

ABAD, Luis V. DE, Azúcar y caña de azúcar. Ensayo de orientación cubana, La Habana, Mercantil, 1945.

O açucar e o quotidiano. Actas do III Seminário Internacional sobre a História do Açucar, Funchal, Centro de Estudos de História do Atlântico, 2005.

Alarcón, Ricardo, Historia de Media Luna, La Habana, Ciencias Sociales, 2002.

AMORES, JuAN B., "Las elites cubanas y la estrategia imperial borbónica en la segunda mitad del siglo XVIII" en Luis Navarro (ed.), Elites urbanas en Hispanoamérica. De la conquista a la independencia, Sevilla, Universidad de Sevilla, 2005, pp. 189-197. 
(ed.), Vitoria y La Habana en tiempos de Espada, Vitoria, Universidad del País Vasco, 2014 (en prensa).

Arango, Francisco, "Discurso sobre la agricultura en La Habana y medios de fomentarla” en Alejandro García-Álvarez y Luis M. García-Mora (eds.), Textos clásicos para la historia de Cuba, [CD-ROM], Madrid, Fundación Mapfre Tavera, 1998 [1792].

Ayala, CÉSAR, American Sugar Kingdom. The Plantation Economy of the Spanish Caribbean, 1898-1934, Chapel Hill, North Carolina University, 1999.

Bahamonde, Ángel y José Cayuela, Hacer las Américas. Las elites coloniales españolas en el siglo XIX, Madrid, Alianza, 1992.

BALbOA, Imilcy, Los brazos necesarios. Inmigración, colonización y trabajo libre en Cuba, Valencia, Centro Tomás y Valiente, Universidad Nacional de Educación a Distancia/ Fundación Instituto de Historia Social, 2002.

"Guantánamo de las tierras del rey a la propiedad contractual" en JosEF OPATRNÝ (ed.), Cambios y revoluciones en el Caribe hispano, Praga, Universidad Carolina, 2006, pp. 123-141.

"El asalto a los realengos en Cuba (1750-1839)" en José A. PIQUeras e Imilcy BALBOA (eds.), La excepción americana. Cuba en el ocaso del imperio continental, Valencia, Universidad Nacional de Educación a Distancia, Fundación Instituto Historia Social, 2006, pp. 55-78.

y Reinaldo Funes, "La tierra en Cuba. Bibliografía básica, fuentes y perspectivas para su estudio”, América Latina en la Historia Económica, núm. 16, 2001, pp. 89-104.

BANDieri, Susana (ed.), La historia económica y los procesos de independencia de la América hispana, Buenos Aires, Prometeo, 2010.

Barcia, Manuel, "El conde de Villanueva y la alternativa de la Cuba Grande. Una aproximación a la labor de Claudio Martínez de Pinillos al frente de la Intendencia de Hacienda de la Isla de Cuba, 1825-185” en GonZÁlez-RIPOll y Álvarez (eds.), Francisco, 2009, pp. 289-300.

BARCIA, MARÍA DEL CARMEN, "La esclavitud en la moderna historiografía americana", Historia Social, núm. 19, 1994, pp. 89-98.

Belmonte, José L., Ser esclavo en Santiago de Cuba: espacios de poder y negociación en un contexto de expansión y crisis, 1780-1803, Aranjuez, Doce Calles, 2011.

Bergad, Laird, Cuban Rural Society in the Nineteenth Century: Social and Economic History of Monoculture in Matanzas, Princenton, Princenton University, 1990.

et al., The Cuban Slave Market, 1790-1880, Nueva York, Cambridge University, 1995.

Bértola, Luis y Pablo Gerchunoff (eds.), Institucionalidad y desarrollo en América Latina, Santiago de Chile, Comisión Económica para América Latina y el Caribe, 2011. 
BIVAR, RAFAEL DE, "Comparando imperios: o lugar do Brasil no projecto escravista de Francisco Arango y Parreño” en GonzÁlez-Ripoll y Álvarez (eds.), Francisco, 2009, pp. 67-84.

Bonera, Miguel, Historia empresarial del ron cubano, Toronto, Lupus, 2005.

Cantero, Justo, Los ingenios. Colección de visitas a los principales ingenios de Cuba, Aranjuez, Doce Calles/Centro de Estudios Históricos de Obras Públicas y Urbanismo/ Consejo Superior de Investigaciones Científicas/Fundación Mapfre Tavera, 2005 (edición de Luis M. García-Mora y Antonio Santamaría, 1a. edición 1856-1857).

CePero, RAúl, Azúcar y abolición. Apuntes para una historia crítica del abolicionismo, La Habana, Cénit, 1947.

Chaviano, Lizbeth, "Trinidad, un estudio del desarrollo azucarero cubano" en III Encuentro de la Asociación de Historia Contemporánea, Bilbao, Universidad del País Vasco, 2012.

y Víctor Echenagusía, "Guaimaro, un museo temático en el Valle de los Ingenios”, Arquitectura y Urbanismo, vol. 30, núms. 2-3, 2009, Cuba, pp. 50-55.

Chinolope [Fernando LóPez-JunQué], Temporada en el ingenio, La Habana, Instituto Cubano del Libro, 1987.

Comín, Francisco et al., Las cajas de ahorros en las provincias de ultramar, Madrid, Confederación Española de Cajas de Ahorros, 2011.

Curry-Machado, Jonathan, "Sin azúcar no hay país: The Transnational Counterpoint of Sugar and Nation in Nineteenth-Century Cuba", Bulletin of Hispanic Studies, vol. 34, núm. 1, 2007, pp. 116-138.

Cuban Sugar Industry: Sugar, Transnational Networks and Engineering Migrants in mid-Nineteenth-Century Cuba, Nueva York, Palgrave, 2011.

"In Cane's Shadow: The Impact of Commodity Plantation of the Local Agrarian Economy on Cuba's Mid-Nineteenth-Century Sugar Frontier" en Jonathan Curry-Machado (ed.), Global Histories, Imperial Commodities, Local Interactions, Basingtoke, Palgrave Macmillan, 2013, pp. 143-168.

(ed.), Global Histories, Imperial Commodities, Local Interactions, Basingtoke, Palgrave Macmillan, 2013.

Dembicz, Andrzej, Plantaciones cañeras y poblamiento en Cuba, La Habana, Ciencias Sociales, 1989.

Denslow, David, Sugar Production in Northeastern Brazil and Cuba, Nueva York, Garland, 1987.

Deerr, Noel, The History of Sugar, Londres, Chapman \& Hall, 1951 (2 vols.).

Dye, Alan, Cuban Sugar in the Age of Mass Production. Technology and the Economics of the Sugar Central, 1899-1929, Nueva York, Stanford University, 1999.

"Privately and Publicly Induced Institutional Change: Observations from Cuban Cane Contracting" en Stefan Haber (ed.), Political Institutions and Economic Growth in Latin America, Stanford, Hoover Institution, 2000, pp. 219-272.

ECHEVARría, ÓSCAR, Captains of Industry, Builders of Wealth: the Cuban Sugar Industry by Miguel Angel Falla, Miami, New-House, 2002. 
Edquist, Charles, Capitalism, Socialism and Technology. A Comparative Study of Cuba and Jamaica, Londres, Zed Books, 1985.

Ely, Roland, Cuando reinaba su majestad el azúcar. Estudio histórico-sociológico de una tragedia latinoamericana, el monocultivo en Cuba: origen y evolución del proceso, Buenos Aires, Sudamericana, 1963.

FERnÁNDEZ, LEIDA, Cuba agrícola, mito y tradición (1878-1920), Madrid, Consejo Superior de Investigaciones Científicas, 2005.

Fernández, Mellén, Consolación, Iglesia, poder y reformismo en la Habana: el episcopado de Juan José Díaz de Espada, 1808-1832, Vitoria, Universidad del País Vasco, 2013.

Fernández, Susan, Encumbered Cuba: Capital Markets and Revolt 1878-1895, Gainesville, Florida University, 2002.

Fernández de Pinedo, Nadia, Comercio exterior y fiscalidad: Cuba, 1794-1860, Bilbao, Universidad del País Vasco, 2003.

"Islas azucareras en el siglo XIX. Cuba, Java y archipiélago filipino" en Martín Rodrigo (ed.), Cuba, de colonia a República, Madrid, Biblioteca Nueva, 2006, pp. 137-155.

et al., Colonial Innovation System, Sub-Imperial Institutions and the Creole Elite in Nineteenth-Century Cuba, Madrid, Universidad Autónoma de Madrid, 2011 (Economic History Working Papers 20/01).

Ferrer, AdA, "El mundo cubano del azúcar frente a la revolución haitiana" en GoNZÁLEZ-RIPOLL y ÁlVAREZ (eds.), Francisco, 2009, pp. 105-116.

Friedlaender, Heinrich, Historia económica de Cuba, La Habana, Montero, 1944.

Fuente, Alejandro, "Sugar and Slavery in Early Colonial Cuba" en Stuart SwarzT (ed.), Tropical Babylon: sugar and the making of the Atlantic world, Chapel Hill, North Carolina University, 2005, pp. 115-157.

FunES, REINALDO, “Tierras cansadas y quemadores de bagazo verde. La interacción con el medio natural y los cambios en la industria azucarera cubana desde mediados del XIX” en PiQUeras (ed.), Azúcar, 2002, pp. 183-213.

From Rainforest to Cane Field in Cuba: an Environmental History since 1492, Chapel Hill, North Carolina University, 2008.

- y Dale Tomich, "Naturaleza, tecnología y esclavitud en Cuba. Frontera azucarera y revolución industrial, 1815-1870” en José A. PiQUeras (ed.), Trabajo libre y coactivo en sociedades de plantación, Madrid, Siglo XXI, 2009, pp. 75-120.

García, Gloria, "El auge de la sociedad esclavista en Cuba" en Historia de Cuba. La Colonia, La Habana, Política, 1994, pp. 218-262.

“Tecnología y abolición” en PIQUeras (ed.), Azúcar, 2002, pp. 214-251.

García, Jenny y YoANKi Fernández, "Industria azucarera en Quemado de Güines" en Monografías.com, Agricultura y Ganadería, publicado el 1 de febrero de 2011 en <www.monografias.com/trabajos82/>. [Consulta: abril de 2013.]

García, Orlando, Esclavitud y colonización en Cienfuegos, 1818-1879, Cienfuegos, Mecenas, 2008. 
e IRÁN CUÉTARA, “Testimonios de construcciones industriales azucareras en Cienfuegos entre 1819 y 1920" en MARTínez et al., Espacios, 2001, pp. 128-138.

García-Álvarez, Alejandro, “Traficantes en el Golfo”, Historia Social, núm. 17, 1993, pp. 33-46.

y Luis M. García-Mora (eds.), Textos clásicos para la historia de Cuba, Madrid, Fundación Mapfre Tavera, 1998 [CD-ROM].

García-Álvarez, Alejandro y Antonio Santamaría, "Azúcar en América" en ANTONIO SANTAMARÍA y AleJANDRo García-Álvarez (coords.), Industria azucarera en América, núm. monográfico, Revista de Indias, núm. 215, 2005, pp. 9-31.

GarcíA-GonzÁlez, ARMAndo, "Francisco Arango y la modernización de la enseñanza científica en Cuba” en González-Ripoll y Álvarez (eds.), Francisco, 2009, pp. 301-324.

GARCÍA-LÓPEZ, JosÉ R., "Los comerciantes banqueros en el sistema bancario cubano" en Consuelo Naranjo et al. (eds.), La nación soñada: Cuba, Puerto Rico y Filipinas ante el 98, Aranjuez, Doce Calles, 1996, pp. 267-292.

García-Mora, Luis M. y Antonio Santamaría, "Esclavos por centrales. Mano de obra y tecnología en la industria azucarera: un ensayo cuantitativo, 1860-1877" en PiQueras (ed.), Azúcar, 2002, pp. 252-271.

García Rodríguez, Mercedes, La aventura de fundar ingenios. La refacción azucarera en La Habana del siglo XVIII, La Habana, Ciencias Sociales, 2000.

Misticismo y capitales: los Jesuitas en la economía de Cuba (1720-1769), La Habana, Ciencias Sociales, 2000.

, Entre haciendas y plantaciones: Orígenes de la manufactura azucarera en La Habana, La Habana, Ciencias Sociales, 2009.

Goizueta-Mimo, FÉlix, Azúcar amargo cubano: monocultivo y dependencia económica, Oviedo, Grafica Summa, 1974.

GonÇAlvès, DominiQue, Le planteur et le roi. L' aristocratie havanaise et la couronne d'Espagne, Madrid, Casa de Velázquez, 2008.

"Francisco Arango o la libertad más allá de la sacarocracia" en GonZÁLEZ-RIPOll y Álvarez (eds.), Francisco, 2009, pp. 213-228.

González, Miguel, "Del esclavo al colono" en Seminario de la cultura del azúcar en Cuba, Catauro, núm. 11 (monográfico), 2005, pp. 57-64.

GonZÁlez, Modesto, Un último escalón alcanzado por la plantación comercial azucarera esclavista, 1827-1886, La Habana, Ciencias Sociales, 2003.

González-Ripoll, María Dolores e Izaskun Álvarez (eds.), Francisco Arango y la invención de la Cuba azucarera, Salamanca, Universidad de Salamanca, 2009.

Guerra, Ramiro, Azúcar y población en las Antillas, La Habana, Cénit, 1927.

Haber, Stefan (ed.), Political Institutions and Economic Growth in Latin America, Stanford, Hoover Institution, 2000.

Hernández SAndoica, Elena, "La historiografía reciente acerca de los españoles en Cuba (siglo XIX): comercio, emigración, negocios y finanzas", Historia y Sociedad, núm. 9, 1997, pp. 149-170. 
História do açúcar. Rotas e mercados, Funchal, Centro de Estudos de História do Atlântico, 2002.

Historia de Cuba. La Colonia, La Habana, Política, 1994.

IGLESIAS, Fe, "Azúcar y crédito durante la segunda mitad del siglo XIX", Santiago, núm. 40, 1988, pp. 119-144.

, "La tierra en Cuba y Puerto Rico en 1899 (Apuntes para un estudio comparado)", Iberoamericana Pragensia, Universidad Carolina, suplemento núm. 5, 1991, pp. 125-144.

, Del ingenio al central, La Habana, Ciencias Sociales, 1999.

"La concentración azucarera y la comarca de Cienfuegos" en MArTínez et al., Espacios, 2001, pp. 85-106.

, "Cuba, la abolición de la esclavitud y el canal de la inmigración jornalera" en PiQueras (ed.), Azúcar, 2002, pp. 76-92.

, Economía del fin de siglo, La Habana, Ciencias Sociales, 2005.

Iglesias, Miguel, Los ferrocarriles de Yaguajay, Yaguajay, s. e., 2003.

IRISARri, ANA, El Oriente cubano durante el gobierno del obispo Joaquín de Osés y Alzúa, Pamplona, Ediciones Internacionales Universitarias, 2003.

JEnKs, Leland, Our Cuban Colony, Nueva York, Vanguard, 1929.

Jofre, José, "The Sugar Industry, the Forests and the Cuban Energy Transition" en CÉSAR Yáñez y Albert Carreras (eds.), The economies of Latin America, Londres, Pickering, 2012, pp. 201-226.

Johnson, Serry, "From Authority to Impotence. Arango's Adversaries and their Fall from Power during the Constitutional Period (1808-1823)" en GONZÁLEZ-RIPOLL y Álvarez (eds.), Francisco, 2009, pp. 193-212.

Kuethe, Allan, Cuba, 1753-1815. Crown, Military and Society, Knoxville, Tennesse University, 1986.

, "El situado mexicano, los azucareros y la fidelidad cubana: comparaciones con Puerto Rico y Nueva Granada" en José A. PIQUeras (ed.), Antillas en la era de las luces y la revolución, Madrid, Siglo XXI, 2005, pp. 201-218.

LAPIQUe, ZOILA y ORLANDO ARIAS, Cienfuegos. Trapiches, ingenios y centrales, La Habana, Ciencias Sociales, 2012.

Lavalle, Bernad, Consullo Naranjo y Antonio Santamaría, La América española, 1763-1898. Economía, Madrid, Síntesis, 2002.

Le Riverend, Julio, Historia económica de Cuba, La Habana, Pueblo y Educación, 1985. Problemas de la formación agraria en Cuba, La Habana, Biblioteca Nacional, 1987.

Lezama Lima, José, "Introducción” en Chinolope [Fernando LóPeZ-JunQUÉ], Temporada en el ingenio, La Habana, Instituto Cubano del Libro, 1987, pp. I-IX.

López, RAFaEL et al., Trinidad y el Valle de los Ingenios, Trinidad, Oficina del Conservador de Trinidad, Consejo de la Administración del Poder Popular/Agencia Española de Cooperación Internacional para el Desarrollo, Junta de Andalucía, 2003. 
LuXán, SAntiago y Ana ViÑa (eds.), El azúcar y el mundo atlántico. Economía y Hacienda: patrimonio cultural y geobotánico, Las Palmas de Gran Canaria, Casa de Colón, 2006. MALUQUer, JORDI, "El mercado colonial antillano en el siglo XIX" en JORDI NADAL y Gabriel Tortella (eds.), Agricultura, comercio colonial y crecimiento económico en España contemporánea, Barcelona, Ariel, 1974, pp. 322-357.

Nación e inmigración, los españoles en Cuba (siglos XIX y XX), Oviedo, Júcar, Archivo de Indianos, 1992.

MARQUÉS, MARÍA ANTONIA, Las industrias menores: empresas y empresarios en Cuba (18801920), La Habana, Ciencias Sociales, 2006.

Marrero, Eduardo, Julián de Zulueta y Amondo. Promotor del capitalismo en Cuba, La Habana, Unión, 2008.

Marrero, Leví, Cuba: economía y sociedad, Madrid, Playor, 1972-1992 (15 vols.).

Martínez, Fernando et al., Espacios, silencios y los sentidos de la libertad: Cuba entre 1878 y 1912, La Habana, Unión, 2001.

Martínez-Fernández, Luis, Torn Between Empires: Economy, Society and Patterns of Political thought in the Hispanic Caribbean, Athens, Georgia University, 1994. Frontier, Plantations and Walled Cities, Princenton, Markus Wiener, 2011.

McAvoy, Muriel, Sugar Barons. Manuel Rionda and the Fortunes of Pre-Castro Cuba, Gainesville, Florida University, 2003.

McGillivray, Gillian, Blazing Cane. Sugar Communities, Class and State Formation in Cuba, Durham, Duke University, 2009.

Moreno Fraginals, Manuel, El ingenio. Complejo económico social cubano del azúcar, La Habana, Ciencias Sociales, 1978.

et al. (eds.), Between Slavery and Free Labor: The Spanish-speaking Caribbean in the Nineteenth century, Baltimore, John Hopkins University, 1985.

Morrison, Allen, "The Hershey Cuban Railway”, publicado el 22 de agosto de 2002, en <www.tramz.com/cu/hy/hy.html>. [Consulta: abril de 2013.]

Muldins, Jack, The Sugar Trust. Henry O. Havemeyer and the American Sugar Refining Company, Columbia, University of South Carolina, 1964.

Nadal, Jordi y Gabriel Tortella (eds.), Agricultura, comercio colonial y crecimiento económico en España contemporánea, Barcelona, Ariel, 1974.

Naranjo, Consulelo, "La población española en Cuba" en Consuelo Naranjo y Tomás Mallo (eds.), Cuba, la perla de las Antillas, Madrid, Doce Calles, 1994, pp. 121-136.

, "El temor a la africanización: colonización blanca y nuevas poblaciones en Cuba” en PIQueras (ed.), Azúcar, 2002, pp. 85-122. , "Cuba, una isla impregnada de guarapo" en GonZÁlEz-RIPOLL y ÁlVAREZ (eds.), Francisco, 2009, pp. 27-40.

(dir.), Historia de las Antillas, Madrid, Doce Calles, 2009 (5 vols.). y Antonio SAntamaría, "De España a las Antillas. Historia e historiografía de la migración española a Puerto Rico y Cuba en las últimas décadas del siglo XIX y primeras del xx”, Migraciones y Exilios, núm. 1, 2000, pp. 161-196. 
Naranjo, Consuelo et al. (eds.), La nación soñada: Cuba, Puerto Rico y Filipinas ante el 98, Aranjuez, Doce Calles, 1996.

Naranjo, Consullo y Armando García GonzÁlez, Racismo e inmigración en Cuba en el siglo XIX, Madrid, Doce Calles, 1996.

Naranjo, Consuelo y Tomás Mallo (eds.), Cuba, la perla de las Antillas, Madrid, Doce Calles, 1994, pp. 121-136.

Navarro, Luis (ed.), Elites urbanas en Hispanoamérica. De la conquista a la independencia, Sevilla, Universidad de Sevilla, 2005.

OpatrnÝ, Josef (ed.), Nación y cultura nacional en el Caribe hispano, Praga, Universidad Carolina, 2003. (ed.), Cambios y revoluciones en el Caribe hispano, Praga, Universidad Carolina, 2006.

"La patria de Francisco Arango" en GonzÁlez-Ripoll y Álvarez (eds.), Francisco, 2009, pp. 167-178.

y Consullo Naranjo (eds.), Visitando la isla. Temas de historia de Cuba, Madrid y Frankfurt, Iberoamericana Verbuet/Asociación de Historiadores Latinoamericanistas Europeos, 2002.

(eds.), Caribe/Caribes. Criollización y procesos de cambio, Praga, Universidad Carolina, 2006.

Ortiz, Fernando, Contrapunteo cubano del tabaco y el azúcar, La Habana, Ciencias Sociales, 1973.

Paz, Manuel y Manuel Hernández, La esclavitud blanca. Contribución a la historia del inmigrante canario en América. Siglo XIX, Fuerteventura, Centro de la Cultura Popular Canaria, 1992.

Pérez, Aisnara y María Ángeles Meriño, Esclavitud, familia y parroquia en Cuba, Santiago, Oriente, 2008.

PÉrez, LuIS, Cuba and United States, Ties of a Singular Intimacy, Athens, Georgia University, 1990.

PÉReZ De la Riva, Francisco, Origen y régimen de propiedad territorial en Cuba, La Habana, Siglo XX, 1946.

Pérez de la Riva, Juan, Para la historia de las gentes sin historia, Barcelona, Ariel, 1976. El barracón y otros ensayos, La Habana, Ciencias Sociales, 1987.

Perret, Alberto, El azúcar en Matanzas y sus dueños en La Habana, La Habana, Ciencias Sociales, 2008.

Piqueras, José A., "El azúcar en Cuba y las fuentes para su estudio", América Latina en la Historia Económica, núm. 11, 1999, pp. 211-232.

(ed.), Azúcar y esclavitud en el final del trabajo forzado, Madrid, Fondo de Cultura Económica, 2002.

"El capital emancipado" en PiQueras (ed.), Azúcar, 2002, pp. 93-114.

, "Relaciones coloniales, intercambios económicos y grupos de poder" en Josef Opatrný y Consuelo Naranjo (eds.), Visitando la isla. Temas de historia de 
Cuba, Madrid y Frankfurt, Iberoamericana Verbuet/Asociación de Historiadores Latinoamericanistas Europeos, 2002, pp. 77-101. Cuba, emporio y colonia. La disputa de un mercado interferido (1878-1895), Madrid, Fondo de Cultura Económica, 2003. 2005. (ed.), Las Antillas en la era de las luces y la revolución, Madrid, Siglo XXI, , "Los amigos de Arango en la corte de Carlos IV" en GonZÁlez-Ripoll y Álvarez (eds.), Francisco, 2009, pp. 151-166. 2009.

(ed.), Trabajo libre y coactivo en sociedades de plantación, Madrid, Siglo XXI, e Imilcy BALbOA (eds.), La excepción americana. Cuba en el ocaso del imperio continental, Valencia, Universidad Nacional de Educación a Distancia, Fundación Instituto Historia Social, 2006.

Quintero, RAmi y Roger Guerrero, Reconstrucción digital de un exponente del patrimonio azucarero, La Habana, Instituto Superior Politécnico José Antonio Echeverría, 2007.

Rodrigo, Martín, Los marqueses de Comillas, Antonio y Claudio López (1817-1925), Madrid, Lid, 2001.

, "Los ingenios San Agustín y Lequeitio (Cienfuegos): un estudio de caso sobre la rentabilidad del negocio del azúcar en la transición de la esclavitud al trabajo asalariado" en PIQUERAS (ed.), Azúcar, 2002, pp. 271-291.

(ed.), Cuba, de colonia a República, Madrid, Biblioteca Nueva, 2006.

"Trasvase de capitales antillanos: azúcar y transformación urbana de Barcelona, siglo XiX” en AnTONio SAntamaría y Consuelo NARAnjo (eds.), Más allá del azúcar. Política, diversificación y prácticas económica, 1878-1930, Aranjuez, Doce Calles, 2009, pp. 127-149.

Rogers, Michael, Sugar Mills of Cuba and their Railway Systems, Canadá, s. e., 2003.

RoldÁn, Inés, Historia económica de Cuba en el siglo XIX, Madrid, Fundación Mapfre, 2001.

La banca de emisión en Cuba (1856-1898), Madrid, Banco de España, 2004. (ed.), Las Haciendas públicas en el Caribe hispano durante el siglo XIX, Madrid, Consejo Superior de Investigaciones Científicas, 2007.

SÁnchez, José, El azúcar en el valle de los ingenios guantanameros, Guantánamo, Mar y Montaña, 2003.

Santamaría, Antonio, "El ferrocarril en las Antillas españolas, Cuba, Puerto Rico y República Dominicana” en Jesús SANZ (comp.), Historia de los ferrocarriles de Iberoamérica (1837-1995), Madrid, Centro de Estudios Históricos de Obras Públicas y Urbanismo, 1998, pp. 289-311.

, "Precios y salarios reales en Cuba, 1877-1914", Revista de Historia Económica, vol. 18, núm. 2, 2000, pp. 339-376.

"Los márgenes de la especialización. La economía cubana, 1790-1880, crecimiento agregado y diversificación" en JOSEF OPATRNÝ y CONSUELO NARANJO 
(eds.), Visitando la isla. Temas de historia de Cuba, Madrid y Frankfurt, Iberoamericana Verbuet/Asociación de Historiadores Latinoamericanistas Europeos, 2002, pp. 103-132.

, Sin azúcar no hay país. La industria azucarera y la economía cubana, 1919-1939, Sevilla, Universidad de Sevilla/Escuela de Estudios Hispano-Americanos-Consejo Superior de Investigaciones Científicas/Diputación de Sevilla, 2002.

"Estimaciones y problemas de los cálculos de renta en Cuba, 1690-1959" en Josef OpatrnÝ (ed.), Nación y cultura nacional en el Caribe hispano, Praga, Universidad Carolina, 2003, pp. 113-133.

"Nuevos temas de historia económica y social de Cuba, siglo XIX: diversificación y economías externas”, Colonial Latin American Historical Review, vol. 14, núm. 2, 2005, pp. 153-190.

"Azúcar, economía y reformas coloniales. Puerto Rico y Cuba" en SANTIAgo LuXÁn y ANA Viña (eds.), El azúcar y el mundo atlántico. Economía y Hacienda: patrimonio cultural y geobotánico, Las Palmas de Gran Canaria, Casa de Colón, 2006, pp. 167-181.

"Economías e identidades agrarias. Jíbaros y colonos en el Caribe español” en Josef Opatrný y Consuelo Naranjo (eds.), Caribe/Caribes. Criollización y procesos de cambio, Praga, Universidad Carolina, 2006, pp. 167-180.

"Temas y controversias del debate histórico internacional reciente en torno a la industria azucarera", América Latina en la Historia Económica, núm. 25, 2006, pp. 123-152.

"Las islas españolas del azúcar (1760-1898). Grandes debates en perspectiva comparada y caribeña", América Latina en la Historia Económica, vol. 18, núm. 1, 2011, pp. 147-176.

"Dos siglos de especialización y dos décadas de incertidumbre. La historia económica de Cuba, 1800-2010” en Luis Bértola y Pablo Gerchunoff (eds.), Institucionalidad y desarrollo en América Latina, Santiago de Chile, Comisión Económica para América Latina y el Caribe, 2011, pp. 147-176.

y AlejANDRo García Álvarez, Economía y colonia. La economía cubana y la relación colonial, 1765-1902, Madrid, Consejo Superior de Investigaciones Científicas, 2004.

(coords.), La industria azucarera en América, número monográfico, Revista de Indias, núm. 215, 2005.

Santamaría, Antonio, y Luis M. García Mora, "Colonos, agricultores cañeros, ¿clase media rural en Cuba?, 1880-1898”, Revista de Indias, núm. 212, 1998, pp. 131-161.

"Donde cristaliza la esperanza, lectura de Los ingenios" en Justo CANTERO, Los ingenios. Colección de visitas a los principales ingenios de Cuba, Aranjuez, Doce Calles/Centro de Estudios Históricos de Obras Públicas y Urbanismo/Consejo Superior de Investigaciones Científicas/Fundación Mapfre Tavera, 2005 (edición de Luis M. García-Mora y Antonio Santamaría, 1a. edición 1856-1857), pp. 9-61. 
Santamaría, Antonio y Consuelo Naranjo (eds.), Más allá del azúcar. Política, diversificación y prácticas económica, 1878-1930, Aranjuez, Doce Calles, 2009, pp. 127-149.

Santamaría, Antonio y Sigfrido Vázquez Cienfuegos, "El Discurso de Arango en su contexto histórico. Un proyecto económico para Cuba o la redefinición de su equilibrio de poderes y relación colonial desde una praxis competitiva 1790-1820", en JuAn B. AmOres (ed.), Vitoria y La Habana en tiempos de Espada, Vitoria, Universidad del País Vasco, 2014 (en prensa).

SANZ, JEsús (comp.), Historia de los ferrocarriles de Iberoamérica (1837-1995), Madrid, Centro de Estudios Históricos de Obras Públicas y Urbanismo, 1998.

SANZ, Vicent, "De la concesión de mercedes a los usos privados" en José A. PIQUERAS (ed.), Antillas en la era de las luces y la revolución, Madrid, Siglo XXI, 2005, pp. 247-273.

“Arango y el mundo del tabaco" en GonzÁlez-RIPOll y Álvarez (eds.), Francisco, 2009, pp. 277-288.

SARTorius, David, "Conucos y subsistencia: el caso del ingenio Santa Rosalía” en Martínez et al., Espacios, 2001, pp. 108-127.

Segrero, Roberto, Conventos y secularización en el siglo XIX cubano, La Habana, Ciencias Sociales, 1988.

Seminario de la cultura del azúcar en Cuba, Catauro, núm. 11 (monográfico), 2005.

Solano, Francisco y Agustín Guimerá (eds.), Esclavitud y derechos humanos, Madrid, Consejo Superior de Investigaciones Científicas, 1990.

SuÁRez, Gladys, "Reseña histórica de Portugalete, Cienfuegos, Cuba" en Monografías.com, Agricultura y Ganadería, publicación 16/01/2009<www.monografias. com/trabajos82/> [Consulta: abril de 2013].

Swartz, StuART (ed.), Tropical Babylon: Sugar and the Making of the Atlantic World, Chapel Hill, North Carolina University, 2005.

Tablada, Carlos y Celia Castelló, La historia de la banca en Cuba, La Habana, Ciencias Sociales, 2008.

Tomich, Dale, Through the Prism of Slavery, Lanham, Rowman \& Littlefield, 2004. , "The Invention of the Cuban Sugarmill" en GonZÁlez-Ripoll y Álvarez (eds.), Francisco, 2009, pp. 113-150.

Tornero, Pablo, Crecimiento económico y transformaciones sociales, Madrid, Ministerio de Trabajo y Asuntos Sociales, 1996.

Trocha 1435, Los ferrocarriles en Cuba, La Habana, Ciencias Sociales, 2009.

"Valle de los Ingenios en Trinidad, Cuba", Arquitectura Cuba/Havana \& Cuban Architecture Blogspot, publicado el 5 de marzo de 2009, en <www.arquitectura-cuba.blogspot.com/2009/05/valle-de-los-ingenios-en-trinidad-cuba.html>. [Consulta: abril de 2013.]

VÁzQuez, Sigfrido, Tan difíciles tiempos para Cuba. El gobierno del marqués de Someruelos, Sevilla, Universidad de Sevilla, 2008.

y Antonio Santamaría, "Cuba económica en tiempos de las independencias Americanas: la Hacienda y la consolidación de los vales reales en compa- 
ración con el caso de México”, Revista de Historia Económica, vol. 30, núm. 1, 2012, pp. 91-124.

VEnegas, Hernán, "Acerca del proceso de concentración y centralización de la industria azucarera en la región remediana a finales del siglo XIX”, Islas, vol. 73, 1995, pp. 117-139.

, "Formación regional y economía en el centro de Cuba" en MARTínez et al., Espacios, 2001, pp. 75-84.

La región en Cuba, Santiago, Oriente, 2001.

Trinidad de Cuba, Trinidad, Oficina del Conservador de Trinidad, 2006.

Venegas-Fornías, Carlos, Cuba y sus pueblos, La Habana, Centro Juan Marilleno, 2001.

"Estancias y sitios de labor: su presencia en las publicaciones cubanas del siglo XIX", Colonial Latin American Historical Review, vol. 10, núm. 1, 2001, pp. 1-26.

VIDAL, ENMA, “Coyunturas favorables de relación entre la Intendencia y el Real Consulado en el fomento de la mano de obra esclava para la agricultura entre 17901804” en GonZÁlez-Ripoll y Álvarez (eds.), Francisco, 2009, pp. 117-132.

YÁÑEZ, CÉSAR, "Economic Modernization in Adverse Institutional Environments: The Cases of Cuba and Chile" en CÉSAR YÁÑEz y Albert Carreras (eds.), The Economies of Latin America, Londres, Pickering, 2012, pp. 133-157.

y Albert Carreras (eds.), The Economies of Latin America, Londres, Pickering, 2012.

ZanetTI, Óscar, Los cautivos de la reciprocidad, La Habana, Ciencias Sociales, 1989.

Comercio y poder: las relaciones cubano-hispano-norteamericanas en torno al 98, La Habana, Casa, 1998. Economía azucarera cubana, La Habana, Ciencias Sociales, 2009.

y Alejandro García-Álvarez, Caminos para el azúcar, La Habana, Ciencias Sociales, 1987.

Zeuske, Michael, "Cuba, la esclavitud atlántica y Alexander von Humbolt” en José A. Piqueras e Imilcy Balboa (eds.), La excepción americana. Cuba en el ocaso del imperio continental, Valencia, Universidad Nacional de Educación a Distancia, Fundación Instituto Historia Social, 2006, pp. 11-27.

y Dale Tomich, "The Second Slavery: Mass Slavery, World Economy and Comparative Microhistories”, Journal of Fernand Braudel Center, vol. 31, núm. 3, 2009, pp. 91-100. 